Purdue University Purdue e-Pubs

5-1999

\title{
The Design and Evaluation of Microphone Arrays for the Visualization of Noise Sources on Moving Vehicles
}

Hyungseok Kook

Kookmin University

Patricia Davies

Purdue University

J Stuart Bolton

Purdue University, bolton@purdue.edu

Follow this and additional works at: http:/ / docs.lib.purdue.edu/herrick

Kook, Hyungseok; Davies, Patricia; and Bolton, J Stuart, "The Design and Evaluation of Microphone Arrays for the Visualization of Noise Sources on Moving Vehicles" (1999). Publications of the Ray W. Herrick Laboratories. Paper 138.

http://docs.lib.purdue.edu/herrick/138

This document has been made available through Purdue e-Pubs, a service of the Purdue University Libraries. Please contact epubs@purdue.edu for additional information. 
The Design and Evaluation of Microphone Arrays for the Visualization of Noise Sources on Moving Vehicles

\section{H. Kook}

Kookmin University

P. Davies, J.S. Bolton, Purdue University

Work funded by Isuzu Motors Ltd. (Hiroshi Takata, contract monitor)

SAE Noise and Vibration Conference \& Exposition Traverse City, Michigan

May 1999 


\section{Motivations of Research}

- For large number of sensors, there exist a vast number of possible arrays

- Need to incorporate increased number of sensors to improve resolution

- for instance, to separate rear tire noise from exhaust noise

- Need different resolutions in x- and z-directions and specific frequency range of interest for standard vehicle passby tests

- -10 to $10 \mathrm{~m}$ in $\mathrm{x}$-direction and 0 to $2 \mathrm{~m}$ in $\mathrm{z}$-direction are observed

- 500 to $2000 \mathrm{~Hz}$

\section{Objectives}

- Develop an efficient 2D-array design method to maximize the visualization capability given a number of sensors

- Evaluate and compare the new method with conventional 2D-array design methods 


\section{Resolution Improvement}

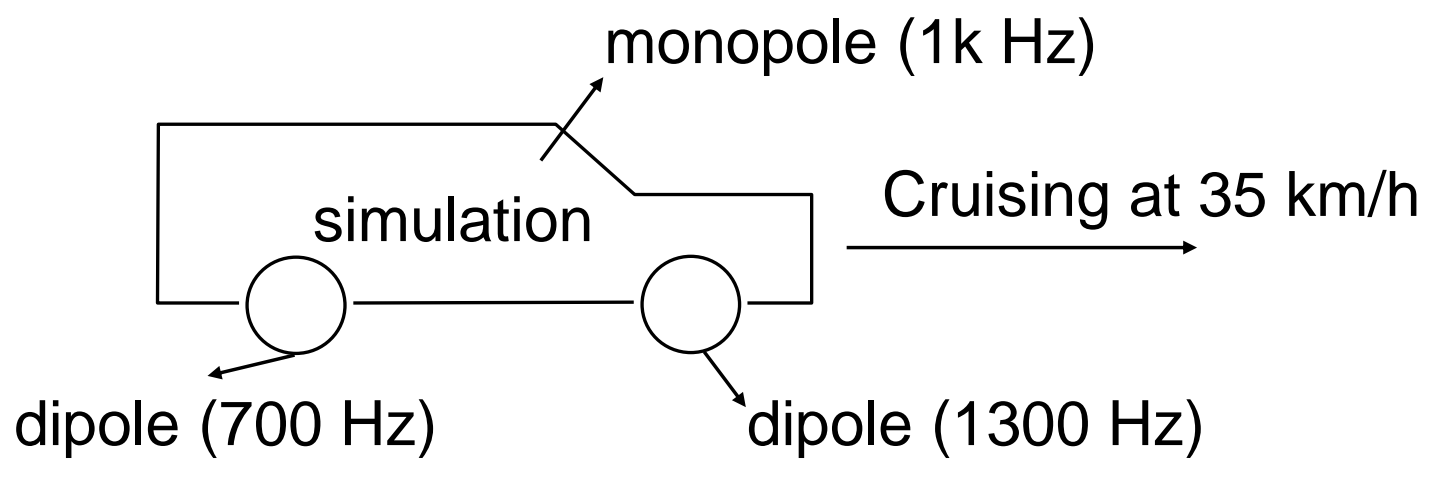

$x=-0.09 \mathrm{~m}$, broadband

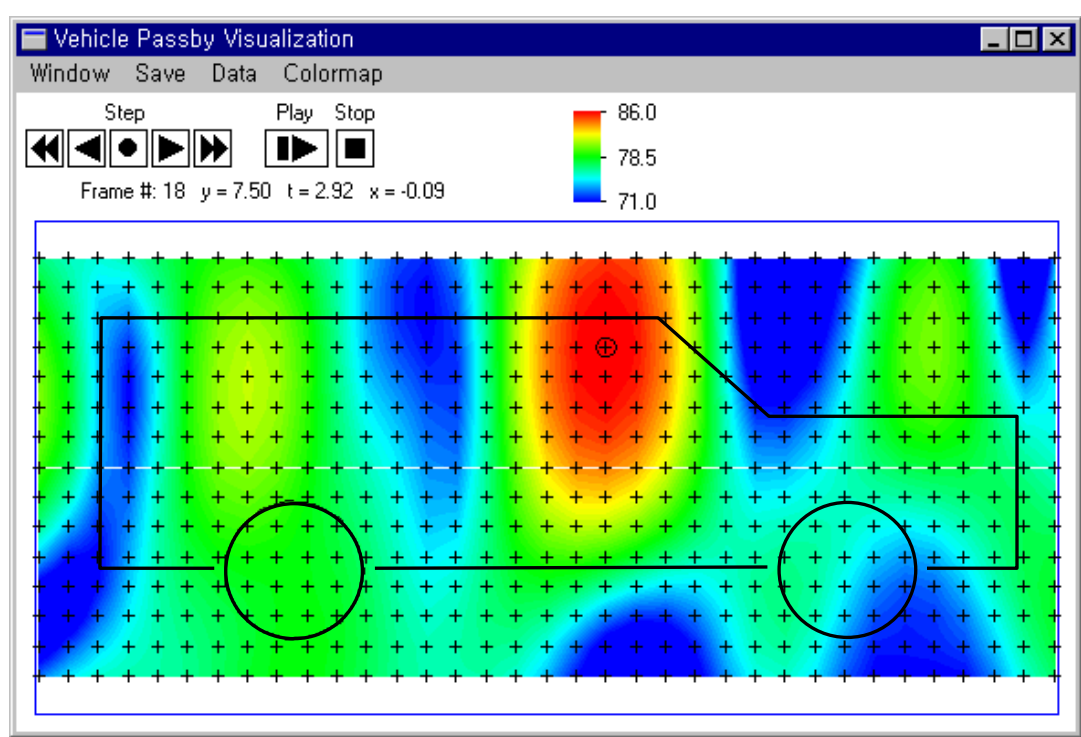

16-microphone array

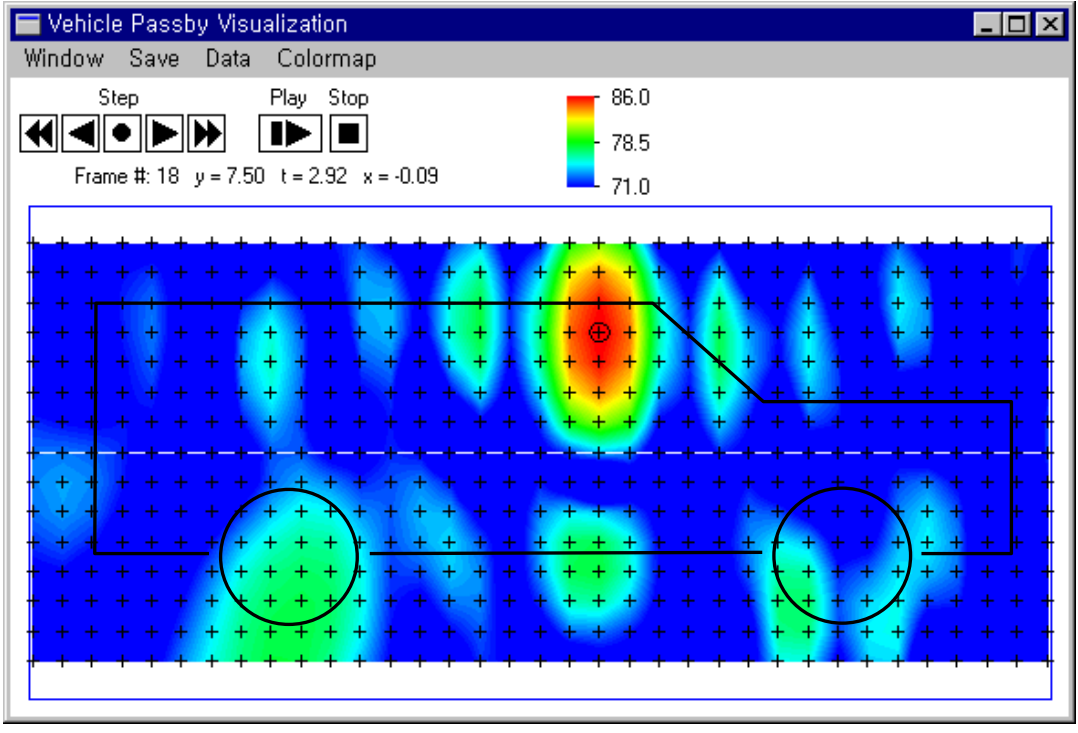

64-microphone array 


\section{$x=-1.90 \mathrm{~m}$, narrow band $(100 \mathrm{~Hz}$ band $)$}
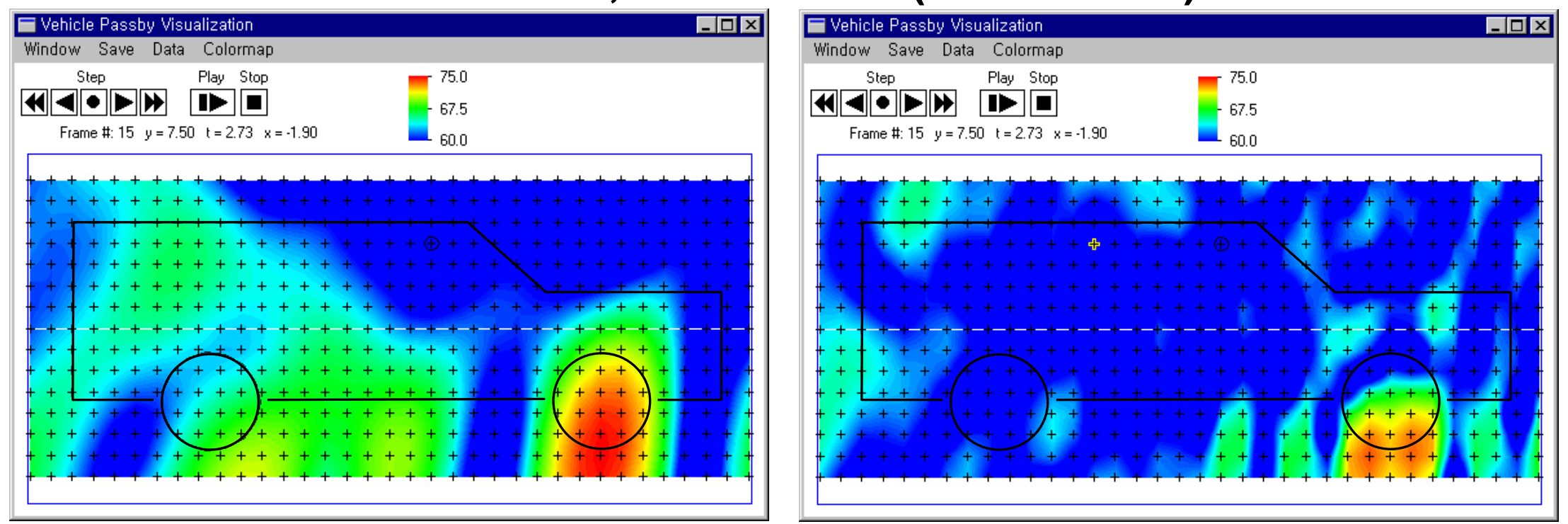

\section{$x=-0.09 \mathrm{~m}$, narrow band $(100 \mathrm{~Hz}$ band)}

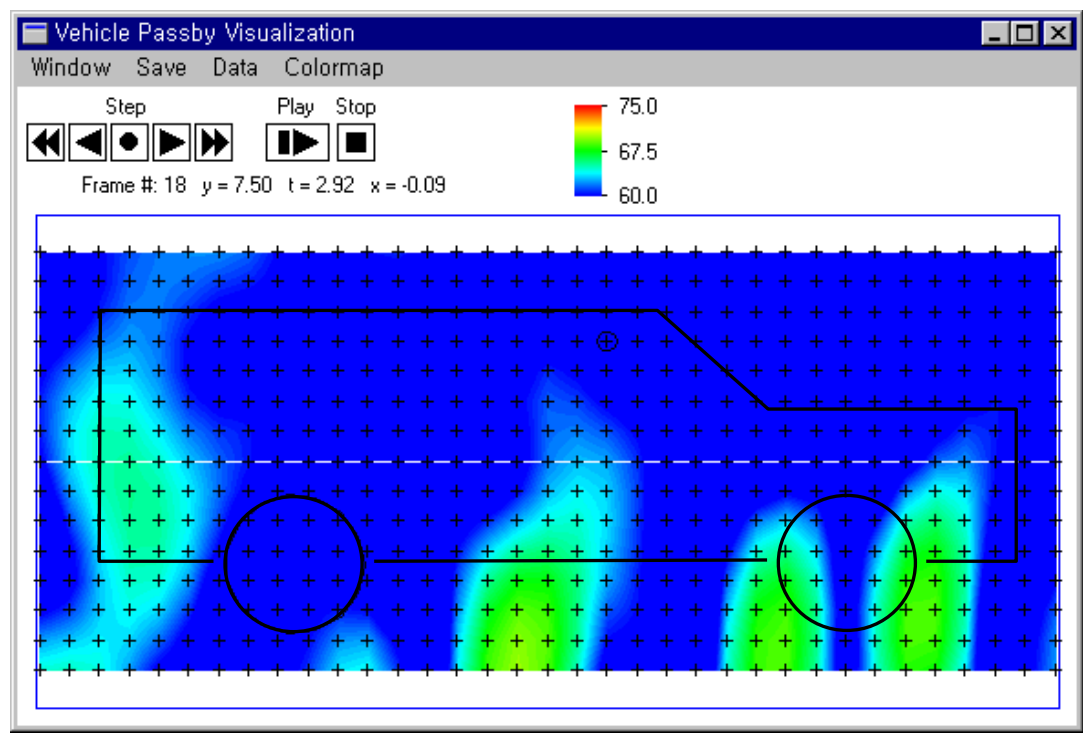

16-microphone array

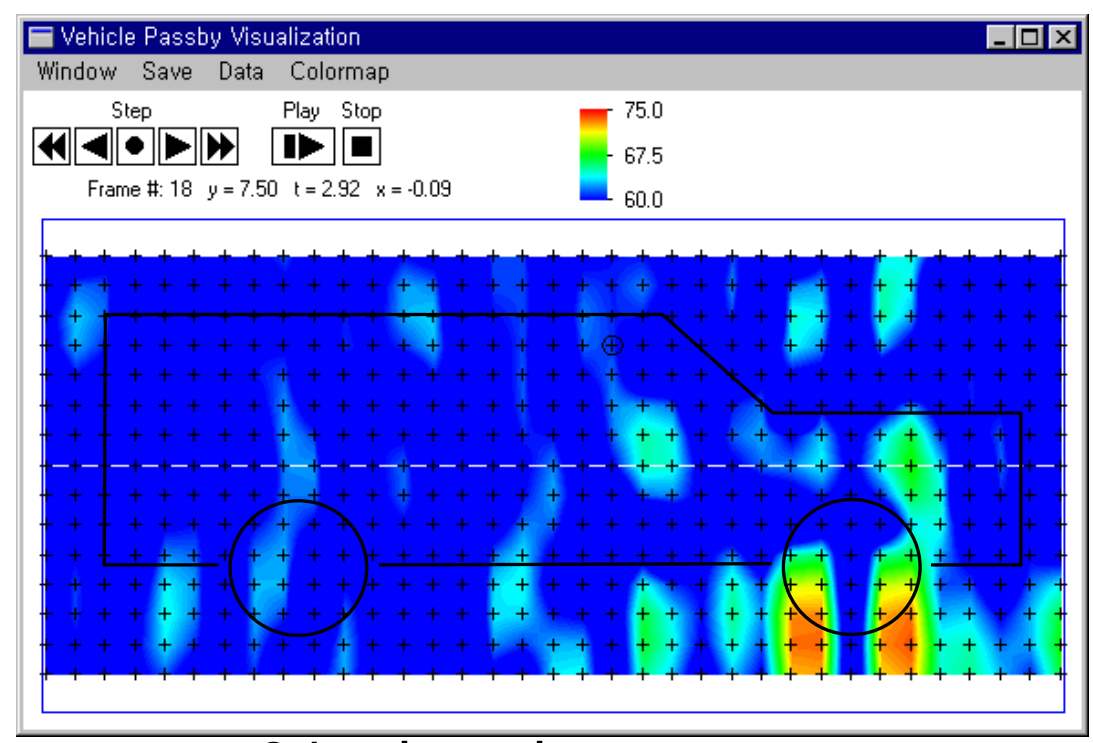

64-microphone array 


\section{Sparse Arrays}

- Conflicting requirements of arrays:

large array aperture (high resolution)

small sensor spacing (anti-spatial aliasing)
= large \# of sensors (for filled arrays) 
- Sparse arrays can be used to obtain similar mainlobe width.

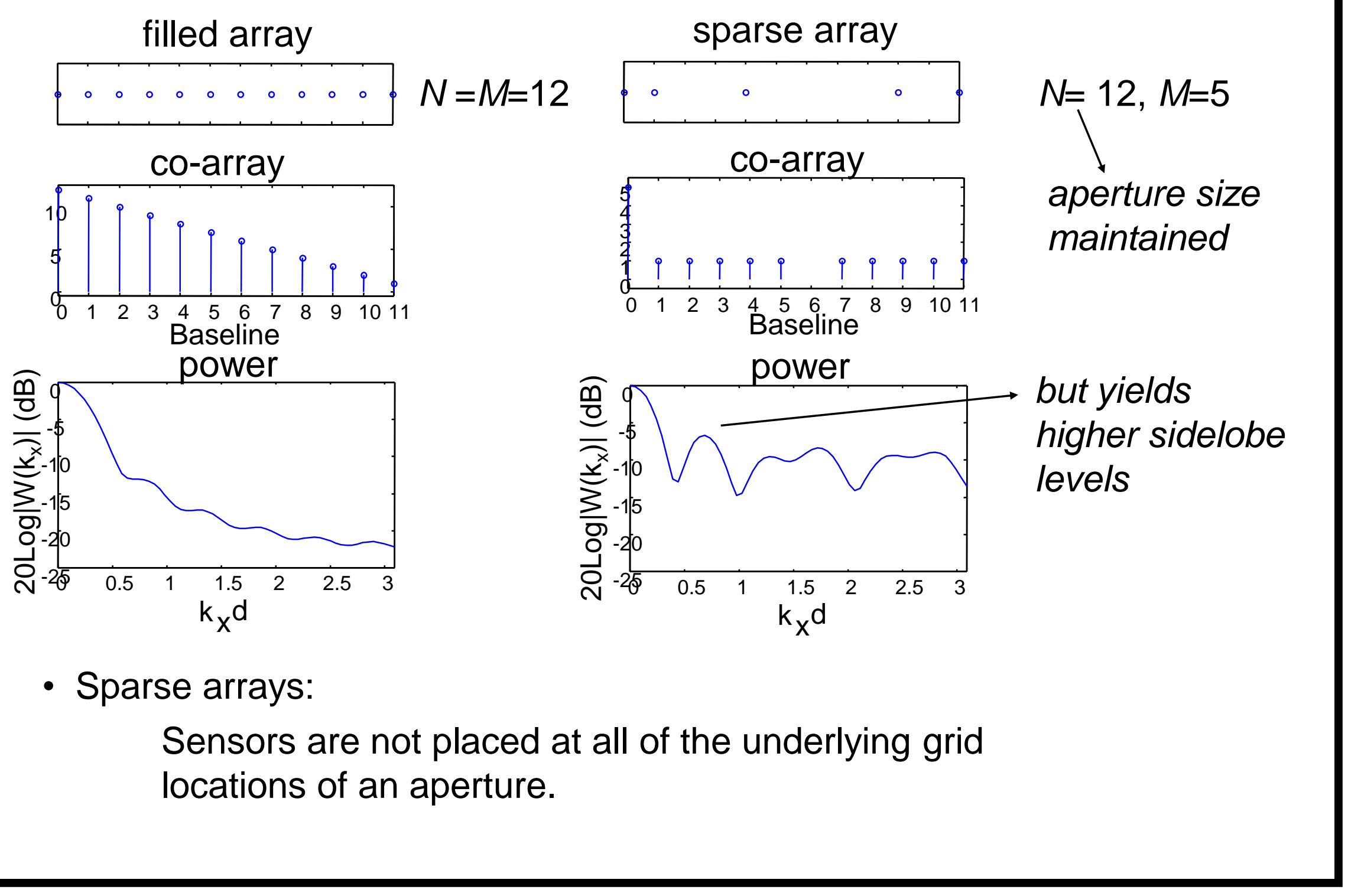




\section{Co-array}

- Continuous form of autocorrelation function:

$$
c(\vec{\chi}) \equiv \int w(\vec{x}) w(\vec{x}+\vec{\chi}) d \vec{x}
$$

- Discrete form:

$$
c(\vec{\chi}) \equiv \sum_{\left(m_{1}, m_{2}\right) \in \mathcal{Q}(\vec{\chi})} w_{m_{1}} w_{m_{1}}^{*}
$$

- Spatial window

- estimate of power spectrum of stationary random field, $S_{f}(\vec{k}, \omega)$ is smoothed by the Fourier Transform of $c(\vec{\chi})$

$$
\operatorname{FFT}\{c(\vec{\chi})\}=\mid W(\vec{k})^{2} \quad \text { (for planar beamforming) }
$$

- that is why mainlobe width remained almost the same as long as the aperture size remained unchanged 


\section{Notes}

- For grid size of $N$ and $M$ \# of sensor, total \# of possible array configurations is ${ }_{\mathrm{N}-2} \mathrm{C}_{\mathrm{M}-2}$ (with two sensors fixed at both ends of the aperture).

- Maximum sidelobe levels differ for each array configuration.

- For linear arrays with $M=<4$ and associated $N(=M(M-1) / 2+1)$, there exist non-redundant arrays with no-gaps in the co-array, which coincide with the array with lowest \# of redundancies.

- For arbitrary numbers of $N$ and $M$, there is no known method to directly solve the "best" array with the lowest maximum sidelobe level in the group of possible array configurations, and correlation btwn \# of redundancies \& maximum sidelobe levels unknown.

for numbers of $N$ and $M$, correlation between \# of redundancies, maximum sidelobe levels and power bandwidths are simulated for linear arrays 


\section{\# of Grid Points = 16, \# of Sensors = 5 (Linear)}

(With first \& Last grid points taken by sensors)

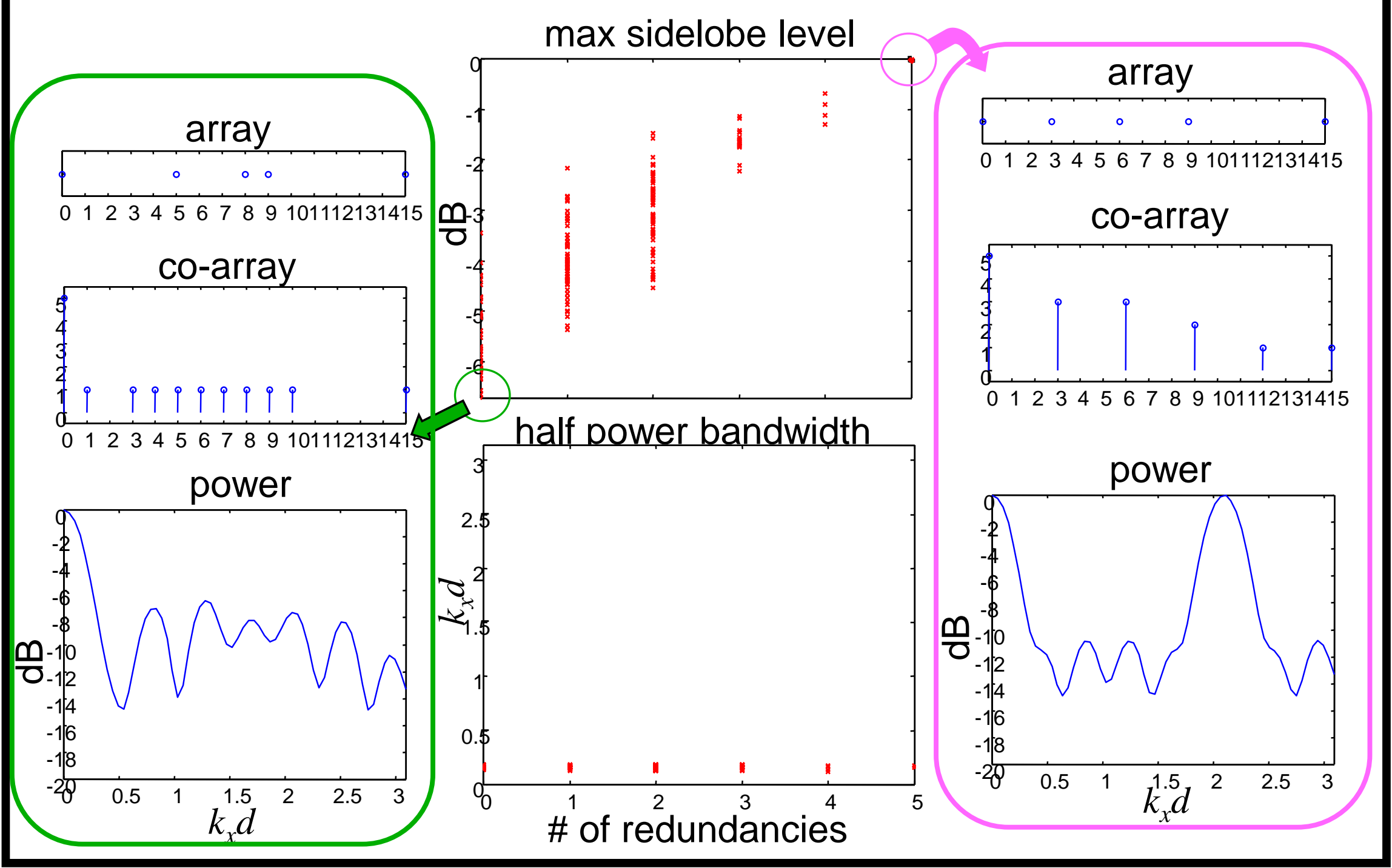




\section{Correlation btwn \# of Redundancies \& Sidelobe Levels}

\# of Grid Points $N=16$

$M=4$,

${ }_{\mathrm{M}} \mathrm{C}_{2}=6<\mathrm{N}-1$

(under packed)

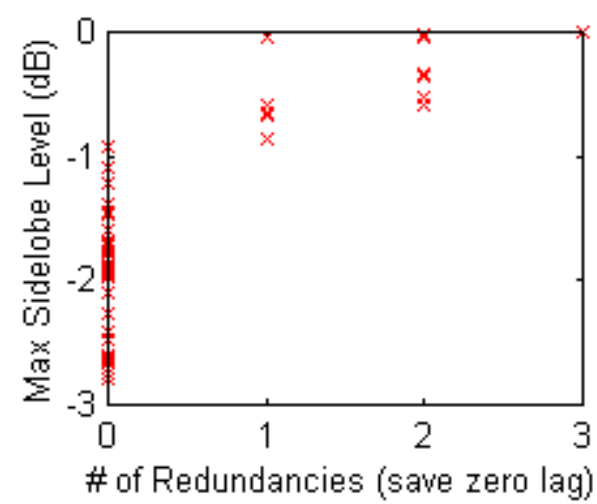

$M=6$,

${ }_{M} \mathrm{C}_{2}=15=N-1$

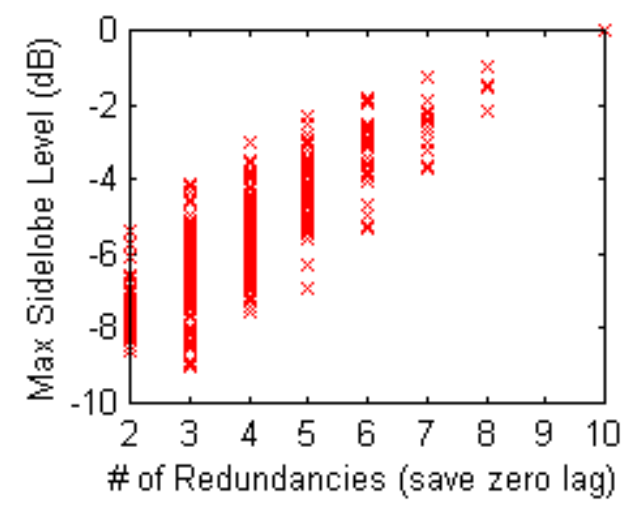

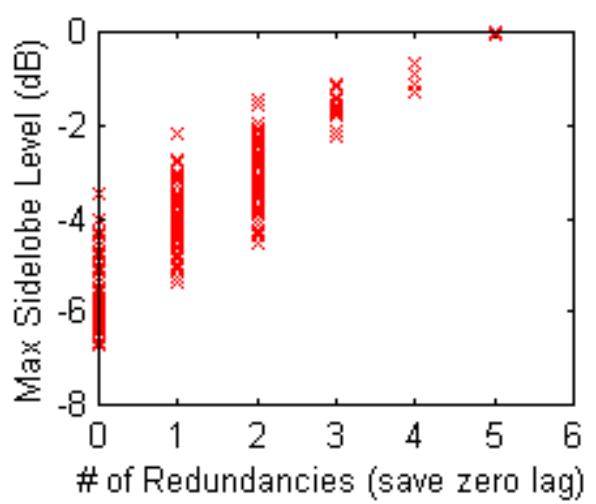

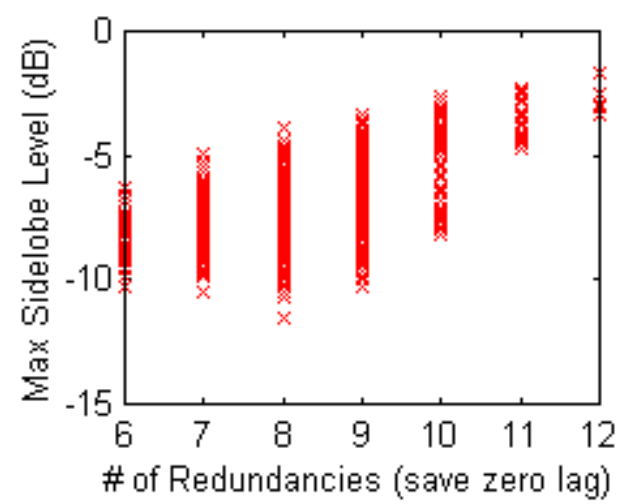

$M=5$,

${ }_{\mathrm{M}} \mathrm{C}_{2}=10<N-1$

(under packed)

$M=7$,

${ }_{M} \mathrm{C}_{2}=21>N-1$

(over packed)

"Under packed" : N-1 greater than \# of possible baselines 


\section{Correlation btwn \# of Redundancies \& Sidelobe Levels}

\# of Grid Points $N=22$

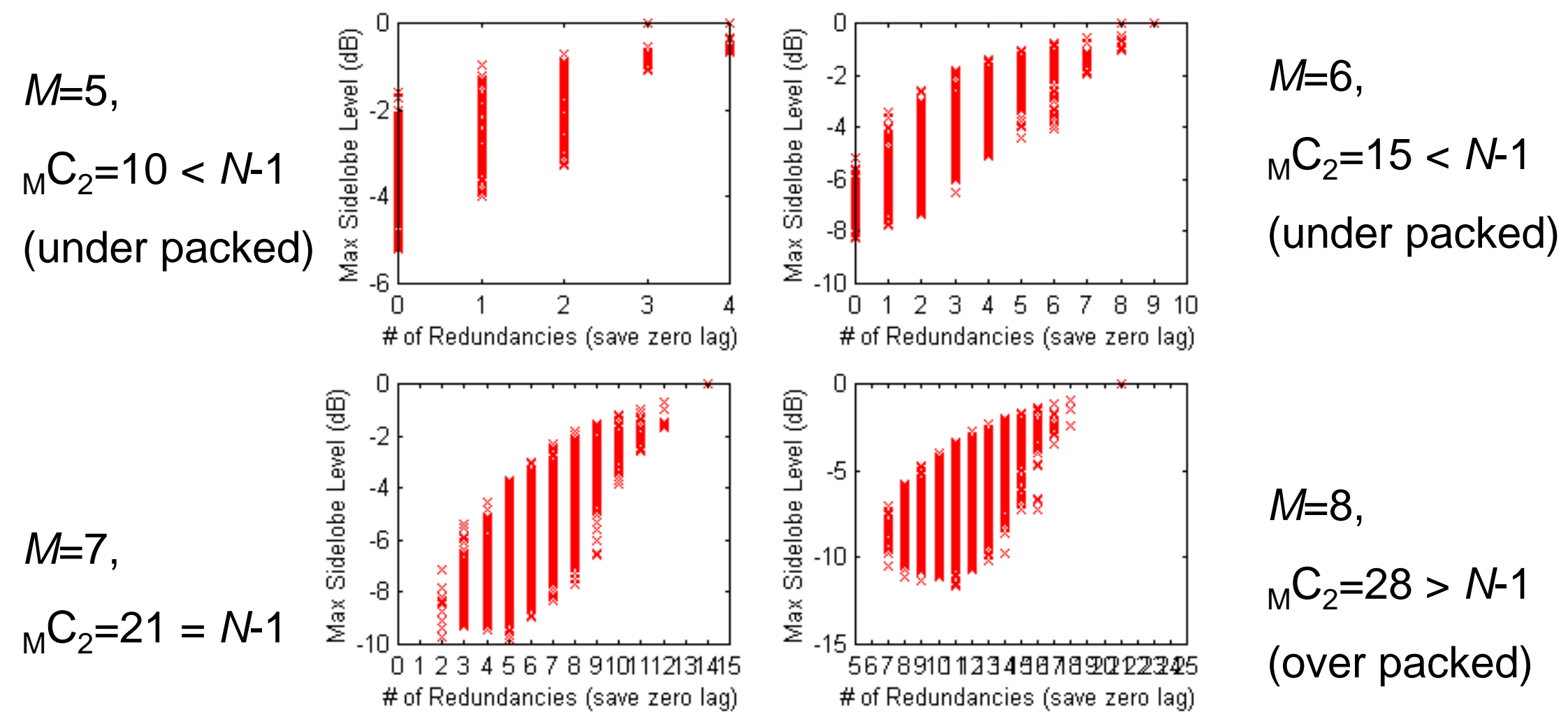

Roughly, low \# of redundancies yields better sidelobe level reductions. 


\section{Summary}

- When under-packed, the array with the lowest maximum sidelobe level is in the array groups with the lowest \# of redundancies.

- Some arrays in the group has higher maximum sidelobe levels.

\section{Design Strategy}

(1) $M$ sensors are placed on the given grid, and the number of redundancies is computed.

(2) a list of a number of best array configurations is maintained based on the \# of redundancies.

(3) repeat step (1) and (2) to test as many array configurations as possible.

(4) compute the powers of the arrays in the list and select the best array (for example by inspection).

A "good" array design method maximizes the chance to "hit" an array configuration with low redundancies in step (1), among the large number of candidate configurations. 


\section{Elliptically Spiral Array Design Method}

parameters: $r_{1}, \phi_{0}$, and $\psi$

mapped and snapped onto the underlying grid

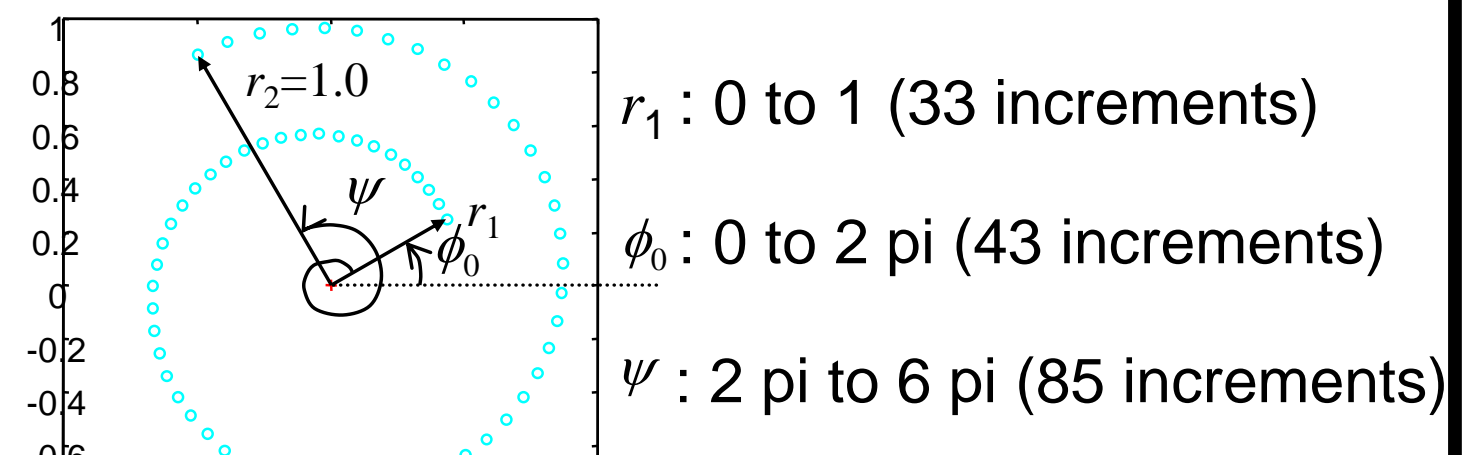

can generate elliptical arrays with non-constant angular spacing (when $\psi$ is not an integer number of $2 \pi$ ). 


\section{Random Array Design Method w/ Segmenting Scheme}

- A random array is an extreme version of a non-redundant array.

- In practice, array elements can "clump" together spatially.

to control the possibility of "clumping" of sensors in one region of the aperture,

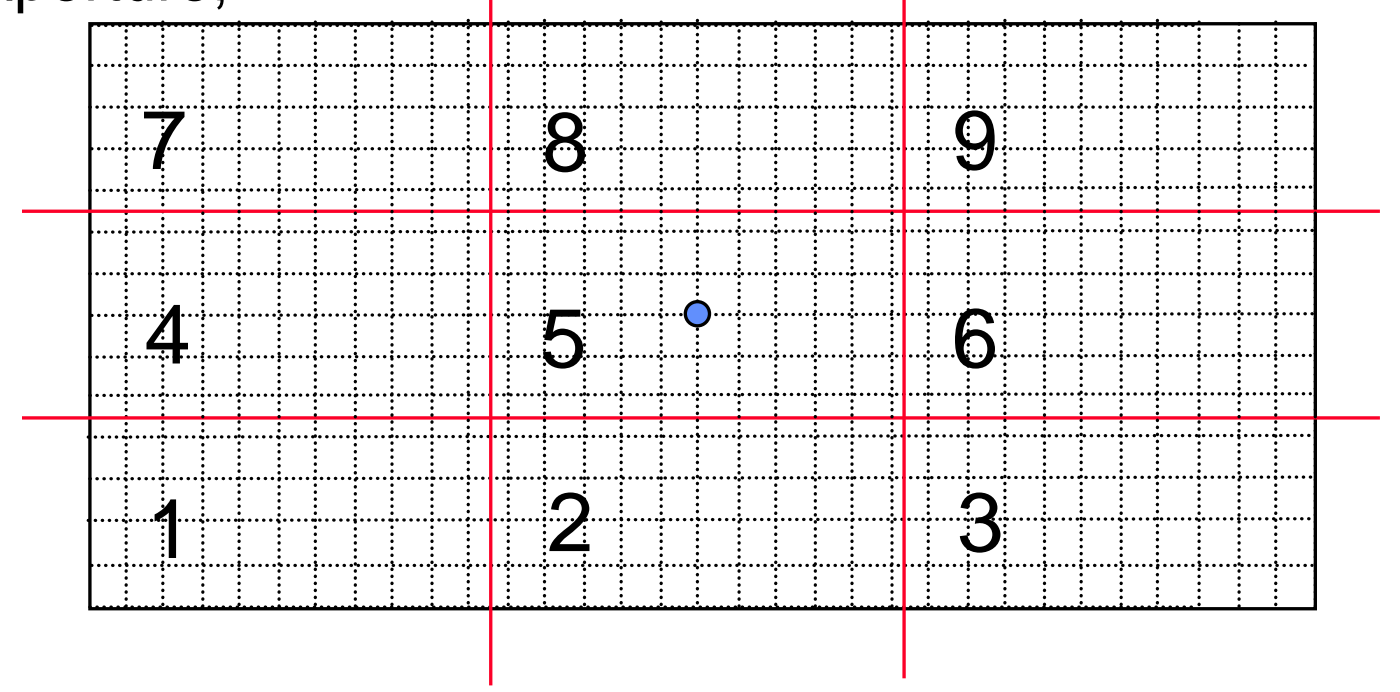

first sensor is placed at the aperture center, then remaining sensors are randomly placed in the subsection in the order

When less than 9 sensors left $->$ in the order of subsection $5,5,4,6,2,8,5,5$ 


\section{Improved Random Array Design Method}

$m=1$;

for $m^{\text {th }}$ sensor;

generate random numbers for unoccupied grid points and sort the grid points(either in ascending or descending order);

compute the further \# of redundancies by taking the grid point as the sensor place;

if \# of further redundancies is zero, place the sensor at the grid point;

if not, investigate the next grid point until a grid point with no further \# of redundancies is found;

if no such grid point exists, choose the grid point with minimum further \# of redundancies;

repeat 


\section{Computation Summary}

$d=8 \mathrm{~cm}$ was determined to avoid aliasing for frequency $2 \mathrm{k} \mathrm{Hz}$.

Array design Input parameters.

\begin{tabular}{|l|l|}
\hline Number of sensors & 64 \\
\hline Best possible baseline (lag) numbers & ${ }_{64} \mathrm{C}_{2}+1=2017$ \\
\hline Grid size & $75 \times 39=2925$ \\
\hline Number of possible array configurations & ${ }_{2925} \mathrm{C}_{64}=? ? ?$ a very large number \\
\hline $\begin{array}{l}\text { Packing ratio = Best possible baseline numbers / } \\
\text { grid size }\end{array}$ & $2017 / 2925 \times 100=68.9 \%$ \\
\hline
\end{tabular}

\section{Results from three different array design methods}

\begin{tabular}{|l|l|l|l|l|}
\hline $\begin{array}{l}\text { Array design } \\
\text { method }\end{array}$ & Run time & $\begin{array}{l}\text { Best } \\
\text { redundancy } \\
\text { obtained }\end{array}$ & $\begin{array}{l}\text { Number of } \\
\text { redundancies in } \\
\text { nonzero lags }\end{array}$ & Occupancy \% in co-array \\
\hline $\begin{array}{l}\text { Random arrays } \\
\text { with segmenting } \\
\text { scheme }\end{array}$ & $\begin{array}{l}\text { 601.9 minutes } \\
\text { (78000 runs) }\end{array}$ & $\mathbf{4 2 7}$ & $427-63=364$ & $(2017-427) / 2925 * 100=54.4 \%$ \\
\hline $\begin{array}{l}\text { The improved } \\
\text { random array } \\
\text { design method }\end{array}$ & $\begin{array}{l}623.1 \text { minutes } \\
\text { (37 runs) }\end{array}$ & $\mathbf{1 8 4}$ & $184-63=121$ & $(2017-184) / 2925 * 100=62.7 \%$ \\
\hline $\begin{array}{l}\text { Elliptically spiral } \\
\text { arrays }\end{array}$ & $\begin{array}{l}672.3 \text { minutes } \\
\text { (120615 runs) }\end{array}$ & $\mathbf{3 1 7}$ & $317-63=254$ & $(2017-317) / 2925 * 100=58.1 \%$ \\
\hline
\end{tabular}




\section{Best 10 Arrays with Minimum Redundancies}

Array \#

modified random array

rank \#1 rank \#2

1

2

3

4

5

6

7

8

9

10

$184 \quad 3 \quad 2$

$184 \quad 4$

9

$184 \quad 6$

$185 \quad 7$

$186 \quad 2$

1878

1919

1921

$194 \quad 5$

19510 elliptical array

rank \#1 rank \#2
31786

$320 \quad 10 \quad 3$

321510

$326 \quad 3 \quad 4$

(326 1

$327 \quad 2 \quad 7$

$328 \quad 4 \quad 2$

$329 \quad 6 \quad 5$

$\begin{array}{lll}329 & 7 & 8\end{array}$

32999 random array with segmenting scheme

427 24

$430 \quad 8 \quad 2$

$433 \quad 7 \quad 3$

$436 \quad 1 \quad 7$

$436 \quad 4 \quad 5$

$\begin{array}{lll}437 & 3 & 9\end{array}$

$437 \quad 10 \quad 1$

$439 \quad 5 \quad 8$

43996

$439 \quad 6 \quad 10$

Arrays were ranked by inspecting power spectrums with source freq. at $f=500$, $1 \mathrm{k}, 1.5 \mathrm{k}$ and $2 \mathrm{k} \mathrm{Hz}$, positioned at $x_{0}=0 \mathrm{~m}$ (rank\#1) and $x_{0}=10 \mathrm{~m}$ (rank\#2). 


\section{Selected Arrays to be Compared}
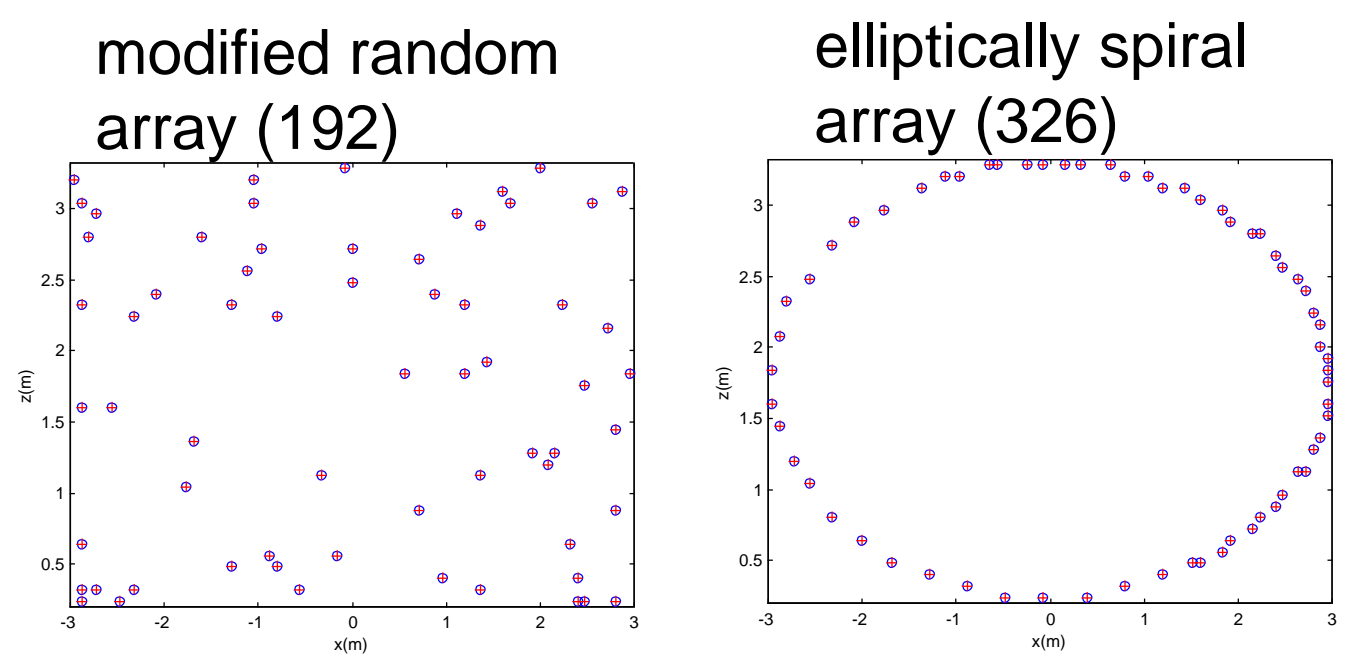

random array with segmenting scheme
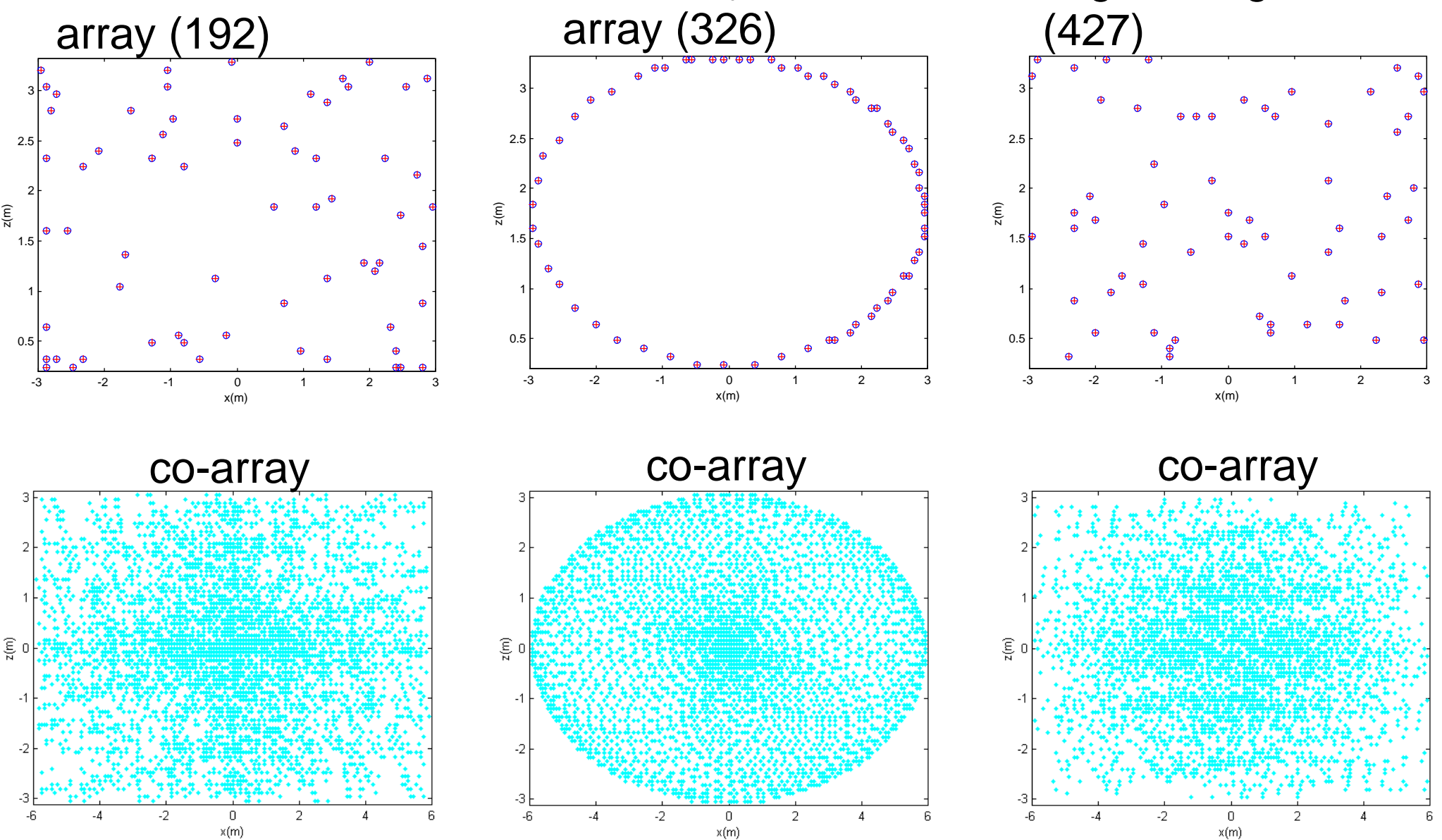


\section{Simulated Power at $x_{0}=0 \mathrm{~m}$}

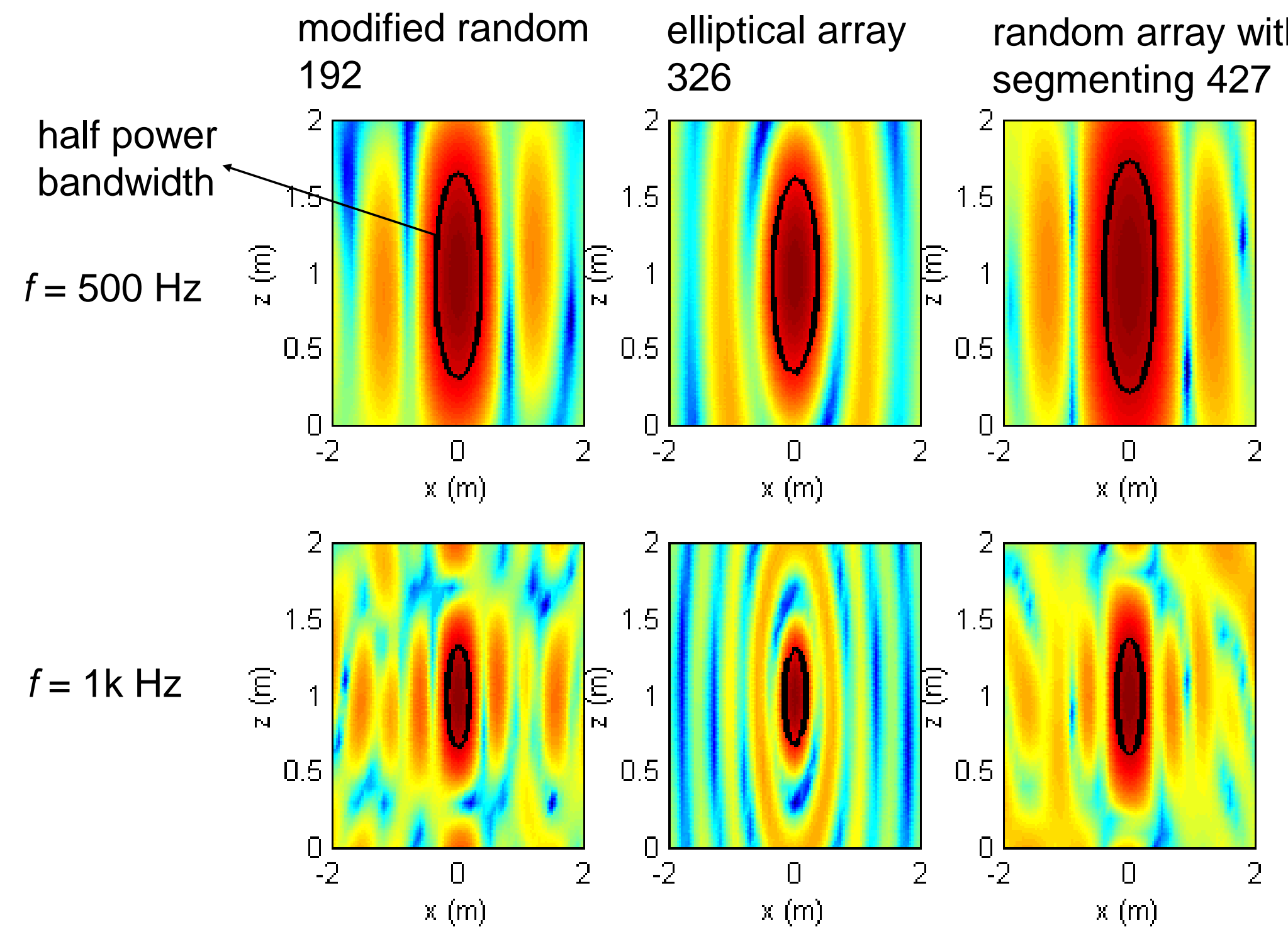




\section{Simulated Power at $x_{0}=0 \mathrm{~m}$}
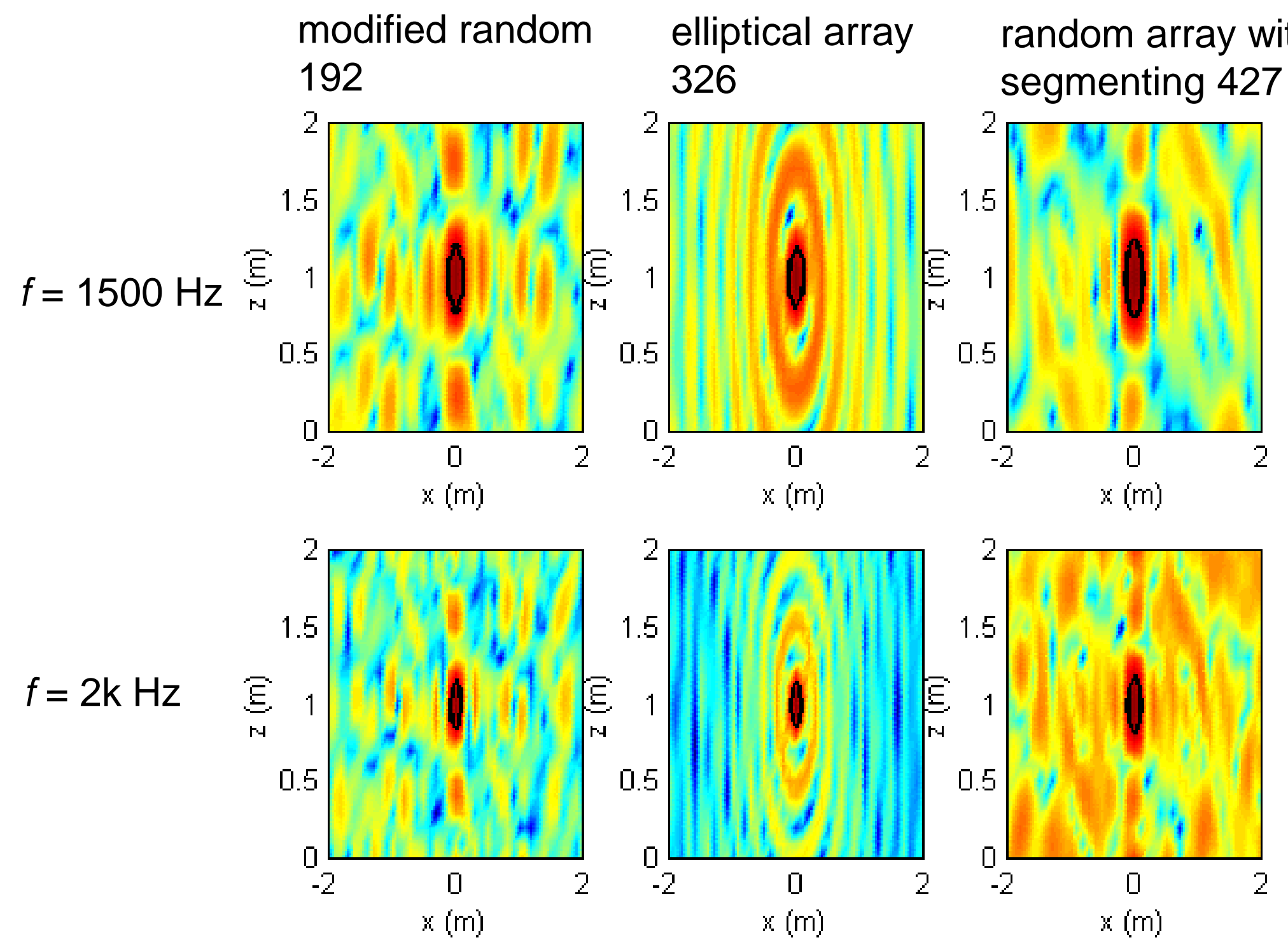


\section{Simulated Power at $x_{0}=10 \mathrm{~m}$}
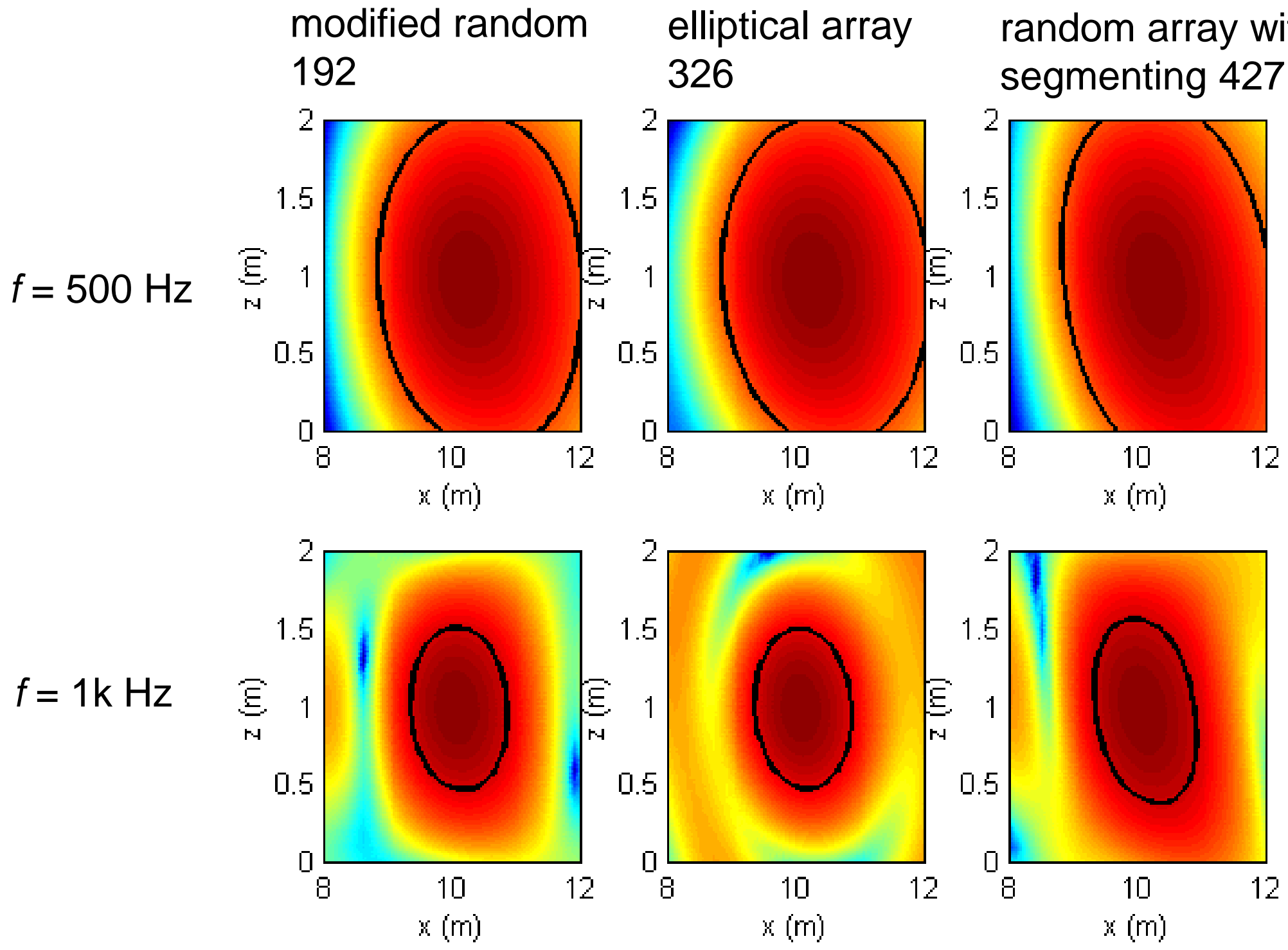


\section{Simulated Power at $x_{0}=10 \mathrm{~m}$}
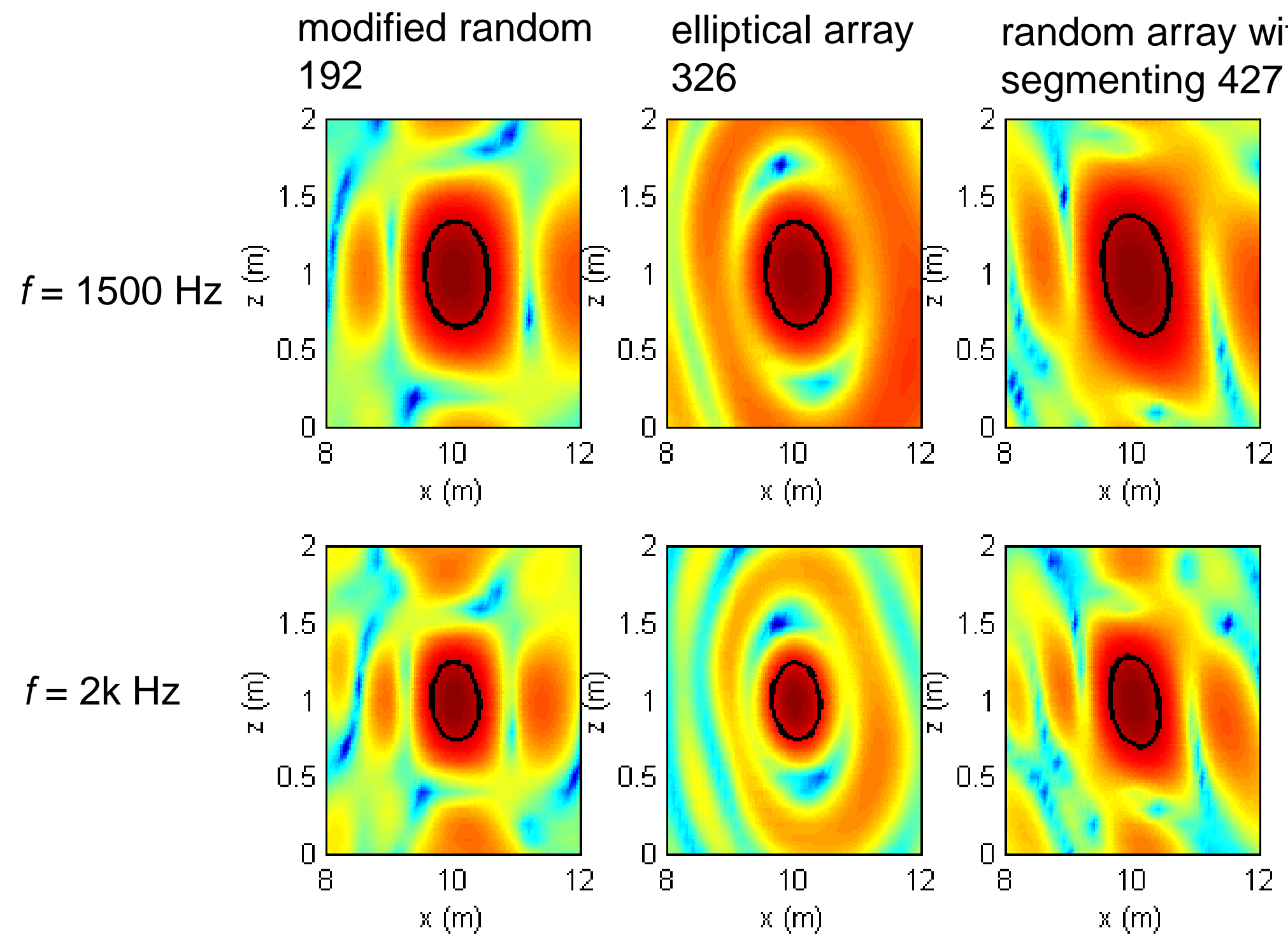


\section{Conclusions}

- An heuristic array design method was developed that can be used for arbitrary shaped grid.

- The new array design method generated array configurations with the lowest numbers of redundancies among the array design methods compared.

- The array generated from the new method yielded narrower mainlobe compared with the array resulted from random array design method with segmenting scheme, and lower sidelobe levels compared with the elliptically spiral array.

\section{Recommendations}

- The number of candidate array configurations which are inspected after the iteration procedure should be increased to enhance the chance to find a good array with relatively higher \# of of redundancies in each group.

- Develop a method to optimize the \# of grid points, $N$, when $M$ sensors are given to increase the array design performance. 